\title{
The Trap of Evolutionary Organicism
}

\author{
Ramsés Fuenmayor ${ }^{1}$
}

This article is a slightly summarised version of an invited plenary at the 3rd Aegean Seminar which took place at the Greek island of Samos in July 1992. The original title was "An Interpretive Systemological View of the Issue: 'Environmental Fluctuations and Cultural Change in Island Societies'.' It is an hermeneutical inquiry into the interpretive context that provides full meaning to the issue of Environmental Fluctuations and Cultural Change. The roots of the relationship of causality embedded in such a title are traced so that the its underlying ontological assumptions are uncovered. This sort of archaeological inquiry will finally unearth the interpretive context that provides full meaning to such a relationship of causality; namely, neo-evolutionary organicism. This theoretical outcome of Modernity embraces natural and social sciences under the aegis of a single way of thinking, feeling and acting which buries the Enlightenment conception of liberty and its consequent problem of morality and of practical reason.

KEY WORDS: interpretive systemology, critical systems thinking, philosophy.

\section{INTRODUCTION: SPEAKING ABOUT OR SPEAKING WITHIN?}

I have been asked to speak about the subject of "Environmental Fluctuations and Cultural Change." Two different ways of speaking "about" a subject like this come to my mind. One is, perhaps, more properly called, to "speak about X." The other could be termed to "speak within X." The latter, "to speak within X," is more common in scientific and technological discourses or in everyday conversation. This type of "immanent discourse" takes for granted a set of assumptions which are, before hand and silently, underpinning the context in which $\mathrm{X}$ has a particular meaning. Of course, because such assumptions are unconsciously taken for granted, we are not aware that such a meaning is a possible one among others. That is to say, we are not aware that we are dealing with one possible interpretation instead of an absolute determination. When we deal with an absolute determination, we are trapped in its interior, for which we do not see boundaries of meaning. "Speaking within the subject X," means to develop some considerations that do not challenge that invisible, and taken-for-granted, context of meaning. We place ourselves "within" the already established boundaries of $\mathrm{X}$ and move only within the

\footnotetext{
${ }^{1}$ Departmento de Sistemolgía Interpretativa. Escuela de Ingeniería de Sistemas. Universidad de Los Andes. Mérida 5101. Venezuela.
} 
discursive space defined by such boundaries. If by accident our discourse bumps into the boundaries, we rapidly come back to the interior because the bump is regarded as a warning that a "contradiction" is about to rise or that "mere talk" is about to start.

The other way, which we have called "speaking about $X$," is intended to understand that taken-for-granted context of meaning of X. Its aim is to trace those untouchable --according to the first way-- boundaries of $X$ so that the unity of the accepted meaning can be seen against its context. In other words, this type of discourse attempts to see $X$ from the outside so that its whole can be appreciated. This "whole" is, of course, not an absolute whole, but the dominating or common meaning. Once this whole-meaning can be seen in its context, other meanings necessarily come to the fore and the otherwise "absolute" meaning looses its "absoluteness."

This "speaking about X" can more properly be called "a critique of X." The phrase, "critique of X," is taken here in a renewed Kantian sense of an examination of the possibilities and limits of our way of experiencing $X$. I say "renewed" because instead of looking for the "necessary a-priori forms," as Kant did, rather we are looking for the non-necessary, historical, "taken-for-granted" conditions that are determining, imposing and making invisible the boundaries of $\mathrm{X}$. We are looking for "forms of power" that reduce X to its current boundaries.

When we, western scholars, living at the end of 20th Century, try hard enough to reach these boundaries and their forms of power, we are doomed to bump against the boundaries of Modernity. The problem at the end of the search, disregarding where reflection started (the provocative subject), is to trace those boundaries of Modernity from a stand outside Modernity. Unfortunately we do not have such a stand because we are trapped within these boundaries by those forms of power. The best we can do is to stand by the boundaries, look outside to what, for us, is an almost empty space and begin to imagine shapes which could constitute an imaginary platform from which Modernity can be seen from outside. The attempt was poetically brought forth by Hölderlin in his poem "To the Germans":

Though your soul roams away, winged with its yearning soars

Far beyond your own time, mournful you linger here,

Cold on desolate shores, with

Your own kind, but estranged from them.

(Hölderlin F: Poems and Fragments. Trans. by Michael Hamberger. London. Routledge and Kegan Paul. p. 59)

Let us attempt to look ahead from this shore of Modernity through the question, "What is taken for granted in our preliminary understanding of the phrase 'Environmental Fluctuations and Cultural Change'?" In order to answer this 
question, I will follow the methodological guidelines of interpretive systemology ${ }^{2}$. However, contrary to the usual procedure in our systems community of announcing methodological guidelines beforehand and wrapping within them the discourse on the subject matter (if there is any), I would rather do it the other way around. In this way, the methodological aspects would rarely loom up out of the thread of the argument.

\section{THE CONTRADICTORY MEANING OF THE PHRASE "ENVIRONMENTAL FLUCTUATIONS AND CULTURAL CHANGE IN ISLAND SOCIETIES"}

According to a semantic analysis, ${ }^{3}$ the phrase, "Environmental Fluctuations and Cultural Change in Island Societies," means that, "constant changes or vacillations in the ecological environment cause changes in the culture of societies which have their ecological niche in islands."

The meaning of the word "culture" in this context is "learned knowledge and skills that distinguish one community from another (...) and which transcend the lives of its living exponents in any one generation" (Lewis, 1976, p. 11). Thus, culture is the "communal spirit" or "collective mind of a society." Such an interpretation carries with it a very important consequence for our inquiry; namely that, our experiencing reality and our thinking are dependent on the communal spirit that constitute the culture to which we belong. This means that our culture traces the boundaries of our concepts and our distinctions concerning reality. This last statement, in turn, brings forth a sort of self-referential paradox in which our phrase is involved: If our thinking and experiencing depends on our culture, the proposition, "environmental fluctuations cause changes in our culture" depends on our culture. In order to see it more clearly, let us examine our discourse according to its logical shape. Let us put a symbolic name "p" to the proposition that states our current interpretation.

p: "Constant changes or vacillations in the ecological environment cause changes in the culture of island societies."

The structure of $\mathrm{p}$ is " $\mathrm{C}$ causes E," where $\mathrm{C}$ (the cause) stands for "environmental fluctuations" and E (the effect) stands for "cultural change" (in the culture of island societies). The effect E are changes in a being B which, in our case is "culture" (of island societies). The conclusion to which we had arrived is that the proposition $\mathrm{p}$ is dependent on the being B affected by the cause C. So we are saying that B is

\footnotetext{
${ }^{2}$ These methodological guidelines and their founding theory can be seen in Fuenmayor and Lopez-Garay, 1991; and Fuenmayor, 1991a, 1991b, 1991c.

${ }^{3}$ This semantic analysis can be seen in the original version of this article presented as a plenary at the $3^{\text {rd }}$ Aegean Seminar on Culture, Knowledge, Communication in Systems (Samos, July 1992), under the title "An Interpretive Systemological View of the Issue: 'Environmental Fluctuations and Cultural Change in Island Societies."

${ }^{4}$ A more extensive discussion about the concept of culture can also be seen in the original version of this paper. See the footnote above.
} 
determining, or put more timidly, conditioning the possibility of defining itself as being affected by $\mathrm{C}$. The being affected by the effect $\mathrm{E}$ of a cause-effect relationship becomes the cause of the cause-effect relationship. Are we playing with words or is there really something strange with our phrase? We seem to have arrived at a paradox. This type of paradoxes are known in logic as self-referential paradoxes. What is the source of this apparent paradox? Maybe we must probe a bit deeper into the meaning of causality in order to clarify this paradoxical issue. But before attempting to probe deeper into causality, let me try to establish a metaphor which could help us see what is happening with our discourse so far.

The meaning we found for our phrase --namely, "Constant changes or vacillations in the ecological environment cause changes in the culture of island societies"-- can be regarded as the visible part of an iceberg. But there is something behind that visible part. It is the submerged, invisible, dark base of the iceberg. However, it is, in our case, a strange base. Instead of serving simply as support for the visible part, it seems to contradict, to plot against, to make fun of, that visible part of the iceberg. What is then the relationship between the visible meaning of our phrase and that other hidden meaning that subverts and contradicts the visible one? What is the source of the contradiction?

In order to answer these questions, it is necessary to plunge deeper into the meaning of our critical intention concerning the subject, "Environmental Fluctuations and Cultural Change". We still must ask: What are the hidden presuppositions in this visible meaning of our phrase? What Weltanschauung is providing that meaning? In order to attempt to answer these questions we need to gain more understanding about the conception of being and of knowledge that underlies this causal relationship between "environmental fluctuations" and "cultural change."

\section{INTRODUCING THE MODERN CONCEPT OF CAUSALITY}

According to Russell Ackoff, after mechanism took control over the Modern scientific Weltanschauung,

\footnotetext{
"It was believed that all interactions between objects, events, and their properties could be reduced by analysis to one fundamental relationship, cause-effect . One thing was said to be the cause of another, its effect, if the first was both necessary and sufficient for the other. An effect could not have occurred unless its cause had, and it had to occur if its cause had. For example, if striking a bell is considered necessary and sufficient for it to make a sound, then the strike is taken to be the cause and the sound to be its effect". (Ackoff, 1974, p. 10).
}

Furthermore, as Kant showed in his Critique of Pure Reason, natural scientific thinking (physics) is compelled to suppose that any possible happening must have a cause. But why was this particular relationship so important? How did it affected other regions of our thinking trapped within the boundaries of Modernity? How was 
causality seen before Modern thinking took hold of our way of appreciating the world? An attempt to answer this last question might shed some light on the others.

According to Foucault (1966), causality was not an important relationship before the dawn of Modernity. In fact, he found four types of relations embedded in explicit formal thought at the end of the Middle Ages: 'convenientia', 'aemulatio', analogia' and 'sympathia' (Foucault, 1966). However, the relationship of causality took their place after the Renaissance and dominated over Modern thought. Again, why did this happen? In school we are taught that the Renaissance was the awakening of the Ancient Greek spirit (thinking and arts). Maybe the sovereignty of causality in thinking was inherited from Ancient Greek thinking. What was then the meaning of causality for ancient Greeks?

\title{
4. THE ANCIENT GREEK NOTION OF CAUSALITY
}

Aristotle paid special attention to defining what, in his days, was understood by causality. Indeed, in the book devoted to "philosophical lexicon" of his Metaphysica, the concept of "cause" occupies the second place in a list of 30 philosophical concepts. What then did Aristotle mean by cause?

\begin{abstract}
'Cause' means (1) that from which, as immanent material, a thing comes into being, e.g. the bronze is the cause of the statue and the silver of the saucer, and so are the classes which include these. (2) The form or pattern, i.e. the definition of the essence, and the classes which include this (e.g. the ratio 2:1 and number in general are causes of the octave), and the parts included in the definition. (3) That from which the change or the resting from change first begins; e.g. the adviser is a cause of the action, and the father a cause of the child, and in general the maker a cause of the thing made and the change-producing of the changing. (4) The end, that for the sake of which a thing is; e.g. health is the cause of walking. For 'Why does one walk?' we say: 'that one may be healthy'; and in speaking thus we think we have given the cause. (Aristotle, 1928, delta, 1013a)
\end{abstract}

Since Medieval times, these four senses of the word "cause" were translated into Western thought, as causa materialis (the matter out of which something is made), the causa formalis (the form or shape into which the matter enters), the causa finalis (the end or purpose to which something serves), and the causa efficiens (that which brings something about).

Nowadays, when we speak about "causality" we mean only causa efficiens, that which brings an effect about. We do not even count the purpose, the end of something, as a cause of that something. But why did Western thinking forget about the other types of causes? Or is it that our present idea of causa efficiens is totally different from the general idea of causality to which Aristotle referred? If we pay heed to Aristotle's text we can see that he was not referring to four "types" of causes. He was referring to the different senses that the single word "cause" might have according to the context in which it was used. This means that this word had a 
single meaning from which the different senses referred to by Aristotle were derived. What was that overall meaning from which the others derived? How different is it from our present meaning of cause?

Before attempting to answer these questions, it is important to step out a minute from the path opened by this questioning in order to see if such a path is not taking us too far away from our original endeavour. Remember, our purpose was to gain comprehension about the implicit assumptions taken for granted in the idea of "environmental fluctuations and cultural change." That is to say, we wanted to gain awareness about the interpretive context in which our phrase has its current meaning. It was shown that the concept of "causality" seems to be the key issue for unfolding the meaning of the whole phrase. All this seems reasonable if we accept the original purpose of this inquiry. However, now we seem to have lost track of our purpose, for we are asking about Ancient interpretations of a word. Why are we interested in the Ancient Greek meaning of the word "cause" if what we really want is to gain further awareness of our current --not the Ancient-- meaning of causality? Is it just in order to give to our inquiry that touch of elegancy provided by "historical backgrounds" and etymology? The answer is simple: We cannot gain critical awareness of the meaning of something unless we step out of the current interpretive context which provides that meaning. Now, we must step out into something else, into another interpretive context from which the former one can be seen. We cannot just float in an empty space of meaning. If we do not attempt this stepping out or stepping back into another interpretive context we are condemned to remain trapped within the boundaries imposed by that current interpretive context which thus becomes invisible. We can know neither what "causality" means nor how that meaning is affecting and being affected by other regions of our interpretive contexts, unless we really try to step out of it so that it loses its imperial power over our appreciation of phenomena. Although we are usually taught that the current Western concept of "causality" was inherited from Ancient Greek Culture, in the following we will present an interpretation of a small region of Greek thinking that contradicts this traditional idea. For this purpose, it seems appropriate to follow Heidegger's idea about the Ancient Greek conception of Being. The immediate reason for choosing Heidegger is simple: Through his late work, Heidegger attempted to show that the Ancient Greek way of experiencing Being was totally different from that developed by European Modernity. Hence, independently of how accurate Heidegger's interpretations of Greek thinking might be considered, they provide an interpretive context that sharply contrasts with our current one. And this is what we need.

According to Heidegger, aition (cause) "had simply nothing at all to do with [our current concept of cause --causa efficiens-- which means] bringing about and effecting." (Heidegger, 1954, p. 290). Aristotle's definition of the word cause was read by Medieval and Modern scholars into the four types of causes. Such reading, however, was performed on the grounds of a way of experiencing Being quiet 
different from that of the Greeks. Hence, the four types of causes were a misinterpretation of the original thinking which spoke about aition. Aition was, according to Heidegger, that to which the coming to presence of something was indebted. "The four causes are the ways, all belonging at once to each other, of being responsible for something else." (p. 290). Heidegger proceeds with an example that clarifies the matter:

Silver is that out of which the silver chalice is made [called later causa materialis of the silver chalice]. As this matter (hyle), it is co-responsible for the chalice. The chalice is indebted to, i.e., owes thanks to, the silver for that of which it consists. ... As a chalice, that which is indebted to the silver appear in the aspect of a chalice, and not in that of a brooch or a ring. Thus the sacred vessel is at the same time indebted to the aspect (eidos) of chaliceness. Both ... [hyle and eidos] are in their respective ways co-responsible for the sacrificial vessel.

But there remains yet a third that is above all responsible for the sacrificial vessel. It is that which in advance confines the chalice within the realm of consecration and bestowal. Through this the chalice is circumscribed as a sacrificial vessel... That which gives bounds, that which completes, in this sense is called in Greek telos, which is all too often translated as "aim" and "purpose," and so misinterpreted. The telos is responsible for what as matter and what as aspect are together co-responsible for the sacrificial vessel.

Finally there is a fourth participant in the responsibility for the finished sacrificial vessel's lying before us ready for use, i.e., the silversmith-- but not at all because he, in working, brings about the finished sacrificial chalice as if it were the effect of a making; the silversmith is not causa efficiens...

The silversmith considers carefully and gathers together the three aforementioned ways of being responsible and indebted. To consider carefully is in Greek legein, logos. Legein is rooted in apophainestai, to bring forward into appearance ... The three previously mentioned ways of being responsible owe thanks to the pondering of the silversmith for the "that" and the "how" of their coming into appearance and into play for the production of the sacrificial vessel.

Thus four ways of owing hold sway in the sacrificial vessel that lies ready before us. They differ from one another, yet they belong together. What unites them from the beginning? (Heidegger, 1954, pp. 291-292).

Heidegger responds to his last question by explaining what being responsible, aitia, was for Ancient Greeks. Being responsible meant "to occasion", in the sense of "starting something on its way to arrival."

The four ways of being responsible bring something into appearance. They let it come forth into presencing. They set it free to that place and so start it on its way, namely, into its complete arrival (Heidegger, 1954, p. 292).

Causality is thus the responsibility in the bringing forth (poiesis) of what becomes and remains present. This bringing-forth is not restricted to handicraft manufacture nor to artistic creation. That which is natural also belongs to this bringing-forth. In Heidegger's words, 


\begin{abstract}
Physis also, the arising of something from out of itself, is a bringing-forth, poiesis. Physis is indeed poiesis in the highest sense. For what presences by means of physis has the bursting open belonging to bringing-forth, e.g., the bursting of a blossom into bloom, in itself. In contrast, what is brought forth by the artisan or the artist has the bursting open belonging to bringing-forth, not in itself, but in another, in the craftsman or artist. (Heidegger, 1954, p. 293).
\end{abstract}

But what is the difference between this "being responsible for" and our current meaning of "cause"? Under our current meaning of causality we could take as equivalent the propositions "environmental fluctuations cause cultural change" and "environmental fluctuations are responsible for cultural change." In general " $\mathrm{C}$ causes E" seems to be equivalent to "C is responsible of the occurrence of E." Hence, is not Heidegger saying the same thing that we all know about causality by means of some vague, obscure, maybe even poetic, terms? The answer is no. Although it is not very clear in Heidegger's essay, the argument for such an answer lies in the idea of "bringing-forth" or "unconcealing", as opposed to the idea of "res corporea" or "bodies" comprised within Modern dualism. Let us examine this difference.

\title{
5. THE MODERN NOTION OF CAUSALITY IN CONTRAST WITH THE ANCIENT GREEK AITION
}

According to our Modern beliefs, this piece of rock is a material thing which exists independently of my existence, of your existence and of any other human being's existence. If we all die suddenly by the effect of a neutron or killing-people bomb, this stone will continue being there. Its existence is independent of our minds. Its being is a fixed being. It has been there and remains there unless another material being destroys it. On the contrary, my feeling of dislike before the idea of a neutron bomb disappears if I disappear. Furthermore, such a feeling will disappear after a moment when I begin to think of something else. In order to "keep it in my mind," to make it last, there must be some affective circumstances or a persistence of the will which holds it there; otherwise, it would vanish. Its existence depends on the continuity of my thinking about it. Its being is a fleeting being due to its mental nature. Material beings, i.e. bodies, on the contrary, carry with themselves their endurance. The condition of remaining there belongs to them.

All this is quiet natural for us. Descartes, one of the great forerunners of Modernity, seems to have believed something similar. According to his writings, there were two types of beings: material beings and mental beings. What-ever-isthe-case was either material or mental. This "either - or" means that the realm of Being is split into two "substances" infinitely different from each other: mind (res cogitans) and matter (res corporea). This is what philosophers call "Cartesian dualism."

So far we feel at home. But how would things look if we did not split the realm of Being in such a drastic way? What this stone would be if I am not conditioned to 
think beforehand that it must be either material or mental? What this stone would be if I am not conditioned to think of myself as a knowing and acting subject which opposes it? On the other hand, how would I experience myself if there would not be that a-priori dualistic opposition? Maybe, the stone would not be a fixed being lying there independent of us. Maybe its being would be nearer to the fleeting character of my feeling of anxiety before the idea of the neutron bomb. (Here I must make a parenthetical warning: I am not meaning to say that in the absence of dualism everything would be mental. That would mean falling in the trap of dualism: whatever-is-the-case is either mental or material; hence, if it is not material it is mental. This is the source of both solipsism and realism).

The overcoming of dualism is as far from realism as it is from solipsism. Both positions arise from the either - or logic of dualism. In the same order of ideas, the question whether what-ever-is-the-case is or is not independent of a knowing-acting subject is grounded on the a-priori exclusive split into mind and matter. Hence the absence of dualism would imply that what-ever-is-the-case does not have to be a property either of the realm of matter or of the mind; it does not have to be either internal or external; it would just be. The question is, "How would it be? This is precisely what we were asking before this parenthetical warning. What then would be the general structure of being. As we were saying, it would not be a thing-initself; maybe it would rather be an act of appearing. Maybe, as Heidegger tells us it was among the Ancient Greeks, it would be a bringing-forth, a presence, an unconcealing which is grounded on concealing. What does Heidegger mean by this and what difference holds between this and our Modern conception?

I think that the Heideggerian idea of unconcealing-concealing can be more easily grasped in the language of interpretive systemology (Fuenmayor, 1991b and 1991c). If we renounce the dogma provided by dualism, we can ask, under a fresh look, how this stone, or what-ever-is-the-case, is possible? This stone is a distinction from what it is not. Just as in the figure-ground examples of the Gestalt school of psychology, the figure, what is being distinguished, cannot be without its ground. Its ground or scene is nothing particular, it is not a distinction, it is just what the distinction is not. If the ground would become a distinction, as we can do with the Gestalt figure-ground, the original distinction would disappear. The figure is thus what appears on the ground of that which does not appear. It is, coming back to Heidegger's terms, what is brought forth to presence and hence unconcealed on the grounds of what is concealed. What is concealed thus becomes the possibilityground for the distinction, for what is present.

Observe that a distinction, what-ever-is-the-case, is not a thing-in-itself; it is an act of appearing. Its endurance is not, like in dualism, given a-priori. Its endurance becomes a problem. Remember that, on the contrary, according to our current dualist-realist idea of reality, material beings carry with themselves their endurance. The condition of remaining there belongs to them. This is why we, Modern people, are not amazed, not even surprised that, when I search in my pocket, I find again the 
"same" stone. This sameness or endurance was a problem for presocratic Greeks because they did not have the ready-made dualistic answer that we now have and which bars the way for the amazement before this mystery. According to dualistic realism, the stone endures because it is independent of the situation in which it appears. If we are not trapped within dualism, everyday bringing-forth becomes a bursting open, a blossoming, before which we are amazed.

This amazement was, precisely, the main source of Greek thinking. Causality, as experienced by the Ancient Greeks, was one of the replies before such an amazement. As explained before, according to Heidegger,

The four ways of being responsible bring something into appearance. They let it come forth into presencing. They set it free to that place and so start it on its way, namely, into its complete arrival. (Heidegger, 1954, p. 292)

But, just as the Greek notion of causality was anchored in the Greek way of experiencing, our notion of causality is anchored in our dualist-realist conception of the world that rules our thematic discourse. Let us briefly see how.

Our realist world is constituted by things (pieces of matter, bodies) and facts. Things are being-in-themselves which exist and naturally endure out there. Facts are space-time relationships that hold among things.

Newtons" "First Law of Motion" was much more that one of the laws of a particular theory. It was a statement of the law that ruled thinking about physics and, later, thinking about anything. If we listen carefully to what this law is saying, we will find the origin where dualistic-realism and our notion of cause merge.

The "First Law of Motion" is the first principle (axiom) of the "Principles or Laws of Motion" ("Axiomata, sive leges motus"). This is the so called principle of inertia (lex inertiae): "Every body continues in a state of rest, or uniform motion in a straight line, unless it is compelled to change that state by a force impressed upon it." This is the fundamental axiom of Modern Physics and, therefore, of mechanism. It must contain the crucial concepts of the new conception of the world. What does it say?

"Every body continues in its state of rest, or uniform motion in a straight line, unless...", speaks of the fixed, enduring, condition of bodies which remain in their condition unless... Notice that Newton is establishing endurance as the essence of material objective reality. If nothing affects the body from outside it has to remain as it is, for it is "naturally" endowed with endurance. If there is change it has to come from outside. And that which produces the change from outside is precisely the cause. The notion of cause (causa efficiens) is thus absolutely necessary for the dualist-realist conception of the world. The conjunction "unless," in "unless it is compelled to change that state by a force impressed upon it," is defining the necessity of the notion of cause. Due to the fixed endurable-in-itself character of material things, the only way to explain change is through the notion of cause. Notice that we seem to believe, in a first instance, that there are causal forces and, 
thereafter, those forces produce effects on fixed beings. According to the findings of the present inquiry and contrary to those current beliefs, in the historical formation of our "world picture," the notion of "cause" is the consequence, the "effect," of the impossibility to explain change when dualism has been adopted and endurance is assumed as the "natural" condition of bodies. Obviously, the appearance of this notion of "cause," which apparently solved the problem of explaining change, reinforced the dualist ontology which was in need of such a notion for its firm constitution.

Now we can see more clearly the difference between our Modern causa efficiens and the Ancient Greek notion of causa. Causa efficiens is an external force that changes the state of a an otherwise fixed and endurable-in-itself being (body). The Ancient Greek aition are the ways of being responsible for the appearance and the endurance of what is not endurable in itself. While our causa efficiens is external to its effect on that which is endurable in-itself, the Greek aition holds sway from within in the appearing and in the mysterious endurance of that which is becoming present (notice the gerunds in "appearing" and "becoming"). The importance of this difference is that each notion of cause is grounded on different ways of explaining Being.

\section{THE MEANING OF "ENVIRONMENTAL FLUCTUATIONS CAUSE CULTURAL CHANGES" UNDER THE INTERPRETIVE CONTEXT OF MECHANISM}

We can now comeback to think about the meaning of our phrase "environmental fluctuations and cultural change in island societies," which, according to the semantic exam performed before, means "Constant changes or vacillations in the ecological environment cause changes in the culture of island societies." Remember that, under the Modern mechanistic conception of cause, "C causes E" means that $\mathrm{C}$ is an external force that produces a change $\mathrm{E}$ on a being $\mathrm{B}$. B is a fixed being whose endurance is not changed unless there is an external cause which produces such change. In our case, the cause $\mathrm{C}$ is environmental fluctuations; the effect $\mathrm{E}$ is a series of changes in the culture of island societies; and, most important, the being $\mathrm{B}$ which experiments changes is the culture of island societies. We have arrived in this way to what might be the source of the self-referential paradox found earlier concerning the relationship of causality in our phrase. According to the Modern mechanistic notion of cause, the being B --culture in our case-- must be a fixed being whose essential endurance can only be changed by means of an external force (cause). However, culture is not a fixed being. As discussed previously, the meaning of culture to which we are referring is that of the "mind," "personality" or "spirit" of societies that live in islands. Hence, within the "either - or" logic of dualism, culture is a mental being which, on the contrary to material beings, is not an endurable-initself being. We cannot, therefore, apply our Modern concept of causality to a nonendurable-in-itself being. It thus seems that we have arrived at a disastrous 
consequence for the subject matter of our present session in this seminar. We have applied the concept of causality to a kind of being to which it cannot be applied. The result of such a contradictory attempt is that we had fallen into a self-referential paradoxical loop explained in section 2.

Thus, can we say that, according to our own Modern way of understanding Being, the phrase "environmental fluctuations cause cultural change" is meaningless? Although we would agree with the former arguments, we still intuit that our phrase is sound and meaningful. If this is the case, are we to disregard this intuition? Not at all. On the one hand, we must attempt to gain a richer understanding of such an intuition of meaningfulness, and on the other hand, we must revise our former arguments. Let us start by the latter.

To be sure, the problem of the realm of beings to which the relationship of causality may be applied, is not new. Indeed, this has been a crucial problem for Modern philosophy. Such a problem reaches its climax in Kantian philosophy, where it becomes the origin of the difference between theoretical reason and practical reason. Let us very briefly explain this last point.

\section{KANT'S ANTINOMY CONCERNING CAUSALITY AND FREEDOM}

We have been trying to understand some aspects of Modern thinking in order to gain awareness about our current meaning of the phrase "environmental fluctuations and cultural change in island societies." Enlightenment has been frequently considered as the great project of Modern thinking. One of the most clear manifestations of the guiding ideas of this project was an essay called "Was ist Aufklärung" ("What is Enlightenment"), written by Immanuel Kant and published in 1784, five years before the French Revolution, and eight years after the Independence of United States of America. In this clear and concise work, Kant defined the Enlightenment as the attainment of autonomy through the use of reason:

\footnotetext{
Enlightenment is man's release from his self-incurred tutelage. Tutelage is man's inability to make use of his understanding without direction from another. Selfincurred is this tutelage when its cause lies not in lack of reason but in lack of resolution and courage to use it without direction from another.... If I have a book which understands for me, a pastor who has a conscience for me, a physician who decides my diet, and so forth, I need not trouble my self. I need not to think, if I can only pay --others will readily undertake the irksome work for me.... Sapere aude! "Have courage to use your own reason!" --that is the motto of enlightenment. (Kant, 1784, p. 85).
}

"Sapere aude!" (Dare to know!) was the motto of the Enlightenment, which in turn was the intellectual and affective heart of Modernity. Indeed, "Sapere Aude!" was a cry for individual autonomy. Its basic intention was to pose the idea of setting oneself free from the cultural power that religion and tradition exercised over the constitution of our Weltanschauungen, and from the natural power that the physical world imposes on one's body. The power force stemming from culture imposes on 
us the way of appreciating the world (perceiving and valuing) and the manner in which we ought to act in it. This first power was Kant's main concern. The second power force constrains us physically, just as it constrains and regulates the rest of the physical world. Reason alone had to be the "inner" sword with which to fight those great cultural and natural forces imposed on us from "outside". Reason should, therefore, tell us from inside, how to appreciate the world, and how we ought to act in it with regard to our fellow human beings. Reason, should indicate how to organise, manage and control the means in order to attain our ends. ${ }^{5}$ The type of reason concerned with how we appreciate the world can be called "theoretical reason". The second type of reason concerned with morals (i.e. how we ought to act) can be termed "practical reason". To answer the question "how we ought to act" implies on the one hand, to decide about our ends, certainly with regard to a variety of possible ends and, on the other hand, to judge about the moral justification of the means to accomplish such ends. The third type of reason, dealing with instrumental possibilities, with which Kant was not concerned but which todays dominates our way of living, can be called, following Habermas, "instrumental reason."

According to Kant, the fundamental question of the practice of morality, "What ought I do?", presupposes the idea of freedom. To ask to my self what possibility should I take among many that are offered within an ethical decision, implies that I am supposing that I am free to decide among them. Otherwise, the moral question would be meaningless. However, this necessary assumption concerning freedom posed a contradiction with regard to Kant's findings regarding theoretical reason and the necessary laws imposed by such a reason on our thinking about nature. The contradiction was displayed in the third antinomy of the Critique of Pure Reason.

According to Kant, every change that occurs in nature has a cause. This is a universal and necessary law of (our thinking about) nature which "allows of no exception" (Kant, 1787, A 536, B 564). Such a law is no more than Newton's First Law of Motion which Kant found to be based on an a priori, and hence necessary, category of our understanding. According to this law, every event in nature is, by ineluctable necessity, causally bound to an infinite chain of former events. In Kant words,

The causality of the cause through which something takes place is itself, therefore, something that has taken place, which again presupposes, in accordance with the law of nature, a preceding state and its causality, and this in a similar manner a still earlier state, and so on. (Kant, 1787, A 445 B 473).

If this universal law of causality holds, I (my will) cannot be the free originator of my actions, for there must always be a former cause. This means that the movement

\footnotetext{
${ }^{5}$ As far as I can see, Kant is not very concerned with controlling nature. Rather, his idea of emancipation is concerned with "release" (Ausgang) from our own prejudices (from our own self-incurred tutelage"), from our inner traps.
} 
of my arm is an effect in which my will is only an intermediary for another cause that is outside myself. My action is thus part of nature and I do not give rise to it spontaneously as the idea of freedom presupposes. This result obviously contradicts the other necessary presupposition of freedom over which the moral question is based. Practical reason (moral reason) is thus founded on the assumption of freedom and theoretical reason is founded on the law of causality that denies freedom. But the problem is even worse than this for, according to Kant, "all thought is an exercise of freedom,... [hence] the very perspective that sees the world as bound in chains of necessity also sees it as containing freedom." (Scruton, p. 59). Indeed, in his Critique of Practical Reason, Kant argues in favour of the "primacy" of practical reason over theoretical reason (Kant, 1786). Hence, the only two ways to solve the antinomy was either to deny freedom or to deny the universality of causality. Kant could take neither solution.

If this Kantian dilemma is seen under an historical perspective, the problem becomes even more acute: The fundamental idea --or as Kant called it, "interest"-of the Enlightenment, namely autonomy, was in clear contradiction with the deepest underpinnings of the ontological position subsumed in Modern thinking. The primacy of "practical reason" simply meant that, according to Kant, this "interest" in autonomy and liberation was more important than any other thing. However, Kant was not in a position to choose between his interest for freedom and a particular ontology based on dualism. The reason for this impossibility was that he was not aware that it was a particular ontology. Indeed, at the bottom of Kant's antinomy there was the limitation of the Modern notion of cause to fixed beings endowed with endurability. Kant could see nothing concerning causality out of such a Modern notion of "cause." He was not aware that the notion of causality was a particular one based on a particular conception of Being. If he would have not been trapped within this notion of causality, which in turn was trapped within a dualist conception of Being, maybe he could have found a solution to the antinomy for the sake of the primacy of practical reason. On the contrary, Kant's alleged solution to his antinomy was directly based on dualism and, in consequence, reinforced it. Put in simple Cartesian words, Kant's alleged solution was as follows: Since there are two infinitely different substances: mind and matter (Cartesian dualism), the laws ruling each one of them must be totally different. Hence, the law of causality operates only in the realm of nature, whereas freedom can be thought only in relation to a "transcendental" realm in which the categories that ruled our thinking about nature not necessarily operate. According to his "solution," the antinomy arises from the fact that I simultaneously belong to the two different realms. So, in order to solve the antinomy I must "conceive and think of my self in this two-fold way" (Kant, 1785 , p. 60). Obviously this last idea contradicts the either-or logic of dualism on whose fundamental premise the solution is based. The adoption of this solution would have had as an immediate consequence the denial of dualism and with it the Modern concept of causality. In other words, the only coherent way to accept Kant's 
alleged solution was to change the concept of causality and the ontological dualism that based it. Kant did not take this last step; hence, he did not solve the problem. He left it for posterity to take care of it. Posterity did solve it. Indeed, as we will see later, posterity took the very possibility that Kant did not want to take, it denied freedom! Posterity forgot about practical reason and about the notion of freedom comprised in the project of Enlightenment. In its place another notion of freedom took possession of our thinking. This judgment is obviously in need of further clarification. Allow me, however, to leave it in stand by. We will take care of it later. Let us now comeback to the contradiction in our phrase.

Remember that our inquiry concerning the relationship of causality between environmental fluctuations and cultural change brought forth a contradiction derived from the impossibility of applying the Modern notion of causality to a nonmaterial or non-natural being. Although, in that inquiry, we had not come across the notion of freedom, it is clear that Kant's antinomy had the same origin as the contradiction regarding causality in our case; namely, the impossibility to apply the concept of causality to a non-natural being. Later we will see that the notion of freedom has a fundamental bearing in the interpretive context that gives full meaning to our phrase.

If we assume our Modern conception of causality and, in general, of Being as a necessary premise, the only possible way to solve the contradiction of our phrase is to hypostatise the notion of culture so that it is thought as if it were an endurable-initself being. Of course, we can attempt to step out of dualism, can not we? In any case, that was not the path followed by the history of our Modern thinking. Along this history, a new alleged solution has been attempted: evolutionary organicism. We will see that it is precisely within evolutionary organicism where our phrase "environmental fluctuations and cultural change" has full meaning for us today. For this purpose we will provide in the following a summarised schema of a "thematic interpretive context" that gives full meaning to such a causal relationship. This is what we will call an "evolutionary organismic interpretive context."

\section{SCHEMA OF AN EVOLUTIONARY ORGANISMIC INTERPRETIVE CONTEXT}

The interpretive context that dominated Modern scientific thought during the first centuries of its development was a mechanistic one. Machines and mechanical relationships constituted the guiding metaphor for thinking and representing every object or relationship among objects. After the creation of the theory of evolution, a slow process towards a universal organismic theory began to take place. Some mechanistic concepts were slowly replaced by organismic ones. As it will be discussed later, this shift from mechanism to evolutionary organicism can be seen as an "evolutionary" process by means of which the Modern conception of the world and of the self has become more coherent with its grounding notions and interests. The resulting evolutionary organicism is also called "systems theory." In the 
following I will attempt to draw a summarised outline of the main principles of a contemporary version of an "evolutionary organismic interpretive context."

\subsection{The Evolutive-hierarchical Constitution of Reality}

The World is a collection of objects (independent things) connected to each other within a universal order. Objects are bodies (res extensa) which, as discussed before, are naturally endowed with endurance. Bodies present a regular "behaviour" derived from their endurable being and from the existence of external causal forces. Such behaviour is given in reference to the space-time grid which is external to bodies. Now, just as the world is constituted by a set of interconnected objects, each object is constituted by a set of interconnected parts whose connected behaviour is the behaviour of the whole object.

The whole may present new properties not present in any of the parts. They are properties which "emerge" from the interconnected behaviour of already existing parts and which are not exhibited by any of the parts in isolation. Accordingly, such properties are called "emergent properties." They are the result (effect) of the multiple interactions of all the parts that constitute the whole. Each whole, conceived in this way, is called a "system."

The possibility of "emergence" gives rise to a hierarchy of levels of reality. Each new level is characterised by being an emergence from the former and by having a higher degree of complexity. In this way, the first level of material existence, which is the basic and primary constitution of reality, gives rise, as an emergent property, to a new level of reality: life. This new level has a higher degree of complexity than the former. Following the same sort of logic, mind is presented as a third level emerging form the second (and from the relationships between the second and the first). Culture is a fourth level emerging from the former.

Nevertheless, "emergence" remains without explanation. We are not able to answer questions such as, "How is it possible that life emerges from non-living stuff?" "How is it possible that the mind can emerge from living cells?" This lack of understanding reveals the existence of "gaps" or "discontinuities" from a hierarchical level to the former. Hence, any sort of relationship between something that belongs to a level and something else that belongs to another level presents a mysterious gap in between the two levels.

\subsection{The Logic of Evolution}

So far we have presented a static schema of a hierarchy that constitutes reality. However, those different levels of complexity are the product of an evolutionary process. Starting from a material level of low complexity, higher levels are reached by means of an evolutionary process of increasing complexity. The evolutionary process is such that the increase in complexity remains within a level until its high degree of organisation reaches a new level. For example, throughout centuries, a slow process of increasing complexity took place within the material level. When 
the complexity was high enough, life emerged from the level of organic matter. How did this happen, we do not know, but we trust it did happened. Again, a very slow process of increasing complexity within the level of biologic life finally gave rise to the mind. Again, how did this happen, we do not know, but we trust it did happened. The interactions of minds gave rise to culture. Again, we do not know how. The increasing process of complexity continues within the higher levels so that both minds and cultures become more and more complex. Could there be a new level of complexity emerging from the level of culture? We do not know yet. However, we do know that societies and their corresponding cultures are evolving.

Observe that the former evolutionary hierarchy is an explanation of reality. Reality is primarily constituted by matter which organises itself into different levels of complexity to give rise to non-material reality. Obviously, within this dualistic ontological position, the basic level of material reality exists independently from the higher levels. In general, a lower level does not require the existence of a higher level, whereas a higher level cannot be without all the lower levels. Hence, my mind, your mind, my discourse, your thinking about my discourse, any possible thinking about reality is dependent (cannot be without) on those lower levels (of which, by the way, we are thinking and talking about). The culture which allows our present communication and the concepts discussed here depend on those lower levels which can exist independently of minds and cultures. Observe that we seem to be falling again in the self-referential paradox described earlier with regard to the relationship of causality in the title of this plenary. ${ }^{6}$ But this last statement goes beyond our interpretive context. Since this is not our present intention, I must come back into our evolutionary organismic interpretive context.

Before the last disrupting comment, we were trying to understand the logic of evolution. Let us come back to it. Evolution is a dynamic process. How is this process put into action? What are the forces that move it? The key to the question about the force that moves evolution from the level of simple life up to the higher levels of humanity is the notion of the "struggle for existence." Each individual struggles against other individuals and against the environment in order to survive. In the less evolved forms of life, the struggle for survival is limited to survival in the moment of the struggle. In more evolved forms of life, the struggle aims at assuring some conditions of power for future survival. In this way, the evolved individual struggles to construct a sort of sphere of protection that provides some conditions of stability. The relationship that results from the struggle among individuals within a restricted environment is competence. The system constituted by a set of competing individuals within a restricted environment is called an ecological niche. The propeller of the whole ecological niche is thus the individual's struggle for survival.

\footnotetext{
${ }^{6}$ According to this interpretive context, the spiritual levels (mind and culture) are dependent on the material levels. However, it should be noticed that the whole relationship of dependence is conceived by the spiritual level.
} 
From the primary forms of Darwinian evolutionism until recent years, the key to the explanation of everything concerning individual or collective behaviour was the struggle for survival of each individual. Within these forms of evolutionism, the living individual was considered as a "closed system." This means that the individual's identity does not change due to its own struggle and to the relationship with the rest of the ecological niche obtained from that struggle. Obviously, although its identity is endurable, such endurability is not so fixed and passive as that of the concept of "body" in Newton's mechanics. While the only possibility to change the spatiotemporal condition of a "body" is by means of an external force (cause), the living organism, due to its high level of organisation, is capable of producing its own movement. Although the living system is primarily constituted by matter (bodies), the organised structure of that constitution produces movement at the level of the living being. It is thus a sort of "autonomous machine." Obviously "autonomy" here means something quiet different from Kant's idea of "autonomy" discussed before. While Kant's idea is founded on the freedom of the will, this autonomy of living systems (including human beings) in the evolutionary organismic perspective is founded on a sort of predetermined impulse for survival. This idea must be borne in mind for a later discussion.

\subsection{The Notion of Causality in Evolutionary organicism}

These forms of evolutionary organicism, which consider the individual as a "closed system," retain the same basic dualist ontological principles of mechanism. But, what happen to the notion of causality? The notion of emergence seems, on the one hand, to retain the basic Modern notion of causality but, on the other hand, such a notion seems to become more complex under evolutionary organicism. Indeed, there is a sort of transcendental causality with regard to each level of the hierarchy. Since higher levels depend on lower levels, higher levels are transformed by "causal forces" stemming from lower levels. We do think that changes which occur in a lower level produce effects in higher levels. This is nothing but establishing a notion of causality that transcends a particular level to have an effect on a higher level. For example, we say that certain psychic disorders are caused by physical changes in the brain; or that environmental fluctuations cause cultural changes. In this way, evolutionary organicism seems to provide an interpretive ground where the wouldbe contradiction in our phrase disappears.

However, when we try to think deeper about this transcendental causality and attempt to rigorously understand how a cause in the lower level produce an effect in the higher level, a mysterious discontinuity is found in the dubious border between levels. Since we do not know how emergence (from one level to another) takes place, we necessarily loose track of our causality chain in the border between levels. Therefore, transcendental causality in evolutionary organicism remains as a sort of ghostlike causality due to this mysterious discontinuity between the two levels. 
But, why does it look like a mysterious discontinuity? Is it not because we are trying to retain the mechanistic concept of causality in order to understand "emergence"? Indeed, if we were thinking in another sort of causality, for example the Ancient Greek aition discussed before, we would not worry about chains of efficient causality.

We have seen that the basic Modern notion of causality is kept within evolutionary organicism. However, whereas, within Newton's mechanics, causality was a fundamental element for conceptual coherency and harmony, within evolutionary organicism, causality is a disrupting element --an unresolved problem for the understanding-- that announces cracks in the conceptual system. But, we seem to have at hand the solution to this problem. Why do we not shift from the mechanistic concept of causality to the Ancient Greek aition? In this way we could deal with a concept of causality that does not force us to look for chains of efficient causality. We cannot, however, do this. As explained at the beginning of the outline of evolutionary organicism, this interpretive context is grounded in dualist-realism. We cannot use the Ancient Greek aition within a conception of Being totally incompatible with such a notion. Remember that aition is meaningful when whatever-is-the-case is experienced as a bringing-forth and not as a being-in-it-self endowed with endurability. Indeed, aition is rooted in amazement before the mystery of endurability.

We have embarked upon outlining the interpretive context of evolutionary organicism with hopes of solving the contradiction concerning causality in the title of this plenary. Under the former arguments it seems that such a choice was not a very lucky one. Although the contradiction has changed its shape under the new perspective, it persists.

There is, however, a new hope to solve our contradiction. There is a revolutionary concept enriching past forms of evolutionary organicism and leading to what we will call "neo-evolutionary organicism." This new concept, introduced in biology by Varela and Maturana (Varela, 1979), might be the solution to the problem of causality within evolutionary organicism.

\subsection{What is new in Neo-evolutionary organicism?}

In a nutshell, the new form of evolutionary organicism conceives of the individual as an "open system" and not as a "closed system." Let us attempt to understand some of the consequences of this fundamental change.

To be an "open system," as opposed to a "closed system," means that the boundaries that define the identity of the individual are not closed and permanently defined. On the contrary, the boundaries that in a particular moment define each individual's identity are continuously being redefined by means of its struggle with the environment in order to keep its identity. Hence, this struggle is the very source of the dynamics of the individual's identity. Observe that although this struggle for maintaining the identity is an individual struggle, it is not, however, an option that 
the individual might or might not take after being an individual. On its side, the identity of the individual is not, within neo-evolutionary organicism, a static beingin-itself that might have "external" and "accidental" relationships with other beings. On the contrary, now the identity of the individual lies in its potentiality to redefine the boundaries of that identity so that it can survive in a particular environment with the greatest degree of stability. Notice that, like in past forms of evolutionary organicism, in neo-evolutionary organicism biological individuals (cells, microorganisms, plants, animals of any sort, including human beings) live within ecological niches. However, according to neo-evolutionary organicism, the relationship with other individuals and with the rest of its environment becomes essential in the constitution of each individual's identity. That relationship obtained among individuals so that each one can maintain a stable identity with regard to its environment is, like in past forms of evolutionary organicism, one of competence.

The competitive process through which the individual is gradually redefining its identity is an evolutionary process. Through such an evolutionary process of continuous struggle, the individual gains in complexity. That gain in individual complexity implies a growing variety and complexity in the ecological niche. In turn, this growing complexity in the whole system or ecological niche implies a tendency to increase the stability of both each individual and the whole system. In this way, the "struggle for existence," in both forms of evolutionary organicism, is translated, at the level of the whole system (ecological niche), in a tendency to increase its stability.

\subsection{Human Ecological Niches in the Optics of Neo-evolutionary organicism}

Human societies are a particular case of ecological niches. Hence, human individuals are particular cases of biological individuals. Remember that, according to our interpretive context, we, human beings, are primarily biological beings which developed an emergent property, the human mind. Just as "inferior" biological individuals do, human individuals assert their identity through the struggle against other individuals and against the environment. Through that struggle, the human individual constructs a sphere of protection in order to assure some stability. Such a struggle also defines the dynamics of the identity of the culture to which the individual belongs. Like in any other ecological niche, the evolution of human societies is originally propelled by the individual struggle for existence and assertion of its identity. Such an individual struggle leads to fundamental relationships among individuals; namely, competition. A systemic order that strengthens the stability of the human ecological niche is generated by competition among individuals in a restricted environment. That order provides rules for competition that prevent the endangering of the stability of the system. Obviously, in such a process, the weakest individuals may be sacrificed to the survival of the fittest and to the consequent gain in the stability of the system. The systemic order in charge of the stability of the 
system is comprised by the culture of the society in question. This culture is then a product of the dynamics of the human ecological niche.

\section{CAUSALITY IN NEO-EVOLUTIONARY ORGANICISM}

We can now easily see that neo-evolutionary organicism is an interpretive context under which our phrase "environmental fluctuations and cultural change in island societies" has full meaning. Human ecological niches are sets of interrelated individuals living in an ecological environment. Each set of interrelated individuals becomes a society by developing a culture. A culture "emerges" from interaction among individuals living within a restricted environment. Just as individuals are involved in a continuous process of defining their identity through their individual struggle, so does the culture of the society to which the individuals belong. Since the relationships of competence among the individuals are restricted and affected by the environment, the dynamics of the culture is also affected by environmental fluctuations.

Nevertheless, in spite of the fact that our phrase has full meaning in neoevolutionary organicism, it is not clear yet if the contradiction regarding the notion of causality disappears under the new perspective offered by neo-evolutionary organicism. Remember that such a contradiction had its most acute form when we attempted to interpret the relationship of causality between environmental fluctuations and cultural change under a merely mechanist interpretive context. Later, when the phrase was examined under an evolutionary-organicist perspective, the contradiction was not so clear. However, when we probed deeper into the meaning of causality under the new interpretive context we found again the contradiction. Finally, neo-evolutionary organicism was introduced in the hope to eliminate the contradiction under its new optics. This new interpretive context retains most of the theoretical structure of past forms of evolutionary organicism. Its novelty lies in a shift from the conception of the individual as a "closed system" to that in which the individual is considered as an "open system." Does the contradiction concerning causality in our phrase really disappear under the consequences of this conceptual shift? Let us see.

As explained before, under the new perspective offered by neo-evolutionary organicism, "environmental fluctuations cause cultural change in island societies" means that, fluctuations in the environment of the ecological niche of island societies cause changes in the dynamic process by means of which the culture of that society redefines its identity. Such a process results from the struggle to maintain the culture's identity while adapting itself to fluctuations in the order of the whole ecological niche. In other words, under natural changes in the physical environment, the whole ecological niche reacts by adapting itself to those changes. Such an overall reaction is conditioned by the reactions of each of the hierarchical levels of the structure of the ecological niche. But does this means that the contradiction concerning causality disappears? 
The problem concerning how emergence takes place obviously subsists in neoevolutionary organicism. This means that the gap in the understanding of causality chains is not overcome by the new conception. However, we must ask again --as we did without success with regard to plain evolutionary organicism-- about the possibility of using another conception of causality, e.g. that of the ancient Greeks, in order to dissolve the problem. Under neo-evolutionary organicism, there seems to be a change in the ontological conception of the individual. It seems as if the individual is not anymore a being-in-itself. Maybe this change can allow another concept of causality like that of the ancient Greeks. In order to reply to this query we must examine carefully the apparent ontological change that is taking place concerning the individual in neo-evolutionary organicism.

The identity of the individual is not fixed. The boundaries that define that identity are changeable in order to increase the adaptive capability of individuals. This means that, as different from the mechanistic conception, according to neoevolutionary organicism, the identity of the individual is apparently not endowed with endurability. Now, is this dynamism in the identity of the individual comparable to the ancient Greek conception concerning bringing-forth? Remember that when what-ever-is-the-case is conceived as an act of bringing-forth, endurability is not "a given" of that which is present. On the contrary, it becomes a source of amazement, for, how can what is conceived as an act remain? On the other hand, if we pay careful attention to the sort of dynamism in the identity of the individual we will discover that, in spite of such apparent dynamism, the basic endurability with which Newton's bodies were endowed is kept in neo-evolutionary organicism. In other words, as comparable to the fleeting character of the bringingforth, the non-endurability of the individual in neo-evolutionary organicism is an illusion. The argument to support this last statement is simple: Suppose that there are not changes in the ecological niche that require the adaptation of the individual by means of the redefinition of its identity boundaries. In this case, the identity of the individual remains without any change. This means that the essence of Newton's first law can be applied to the individual in the context of neo-evolutionary organicism. Certainly, the law of inertia, in the context of neo-evolutionary organicism, would state something like this: "Every individual maintains its identity unless it is compelled to change the boundaries of that identity by forces stemming from the ecological niche and impressed upon it." This is enough to show that the changes brought about by neo-evolutionary organicism with regard to the nature of the individual keep the dualist core of Modernity. Endurance still lies at the essence of the individual as conceived by neo-evolutionary organicism. In consequence, the concept of causality held in this new interpretive context, although some how disguised, keeps its basic Modern mechanistic core.

So far we can conclude the following. The interpretive context that we have called neo-evolutionary organicism, as compared to other previous modern interpretive contexts and in contrast with the outline of the ancient Greek way of 
experiencing Being (another interpretive context), provides a richer meaning to the phrase "environmental fluctuations and cultural change in island societies." It also shows, however, that the phrase is meaningful by hiding an inner contradiction (remember the metaphor of the iceberg).

One objection could be raised against this conclusion: All the neo-evolutionaryorganicist characteristics presented before are not really specific of human societies; they are common to any ecological niche. The objection would be that we have arrived at a conclusion regarding the meaning of the phrase that refers to the culture of certain types of societies, without considering the specific characteristics that neoevolutionary organicism takes within human ecological niches. The reply to this would-be objection would allow us to gain further awareness about the interpretive context of our phrase which, as you remember, is our aim in this talk. What is then the specific shape that such characteristics take in human societies? More concretely, how do human individuals assert their identity in evolved human niches? What is the form of that evolved systemic order that can allow the assertion of individuality? The answers are provided by the dominating economic and political theory of modernity, liberalism. Liberalism can be seen as the theoretical specificity of evolutionary organicism with regard to human ecological niches (human societies).

\section{LIBERALISM: THE POLITIC-ECONOMIC APPENDIX OF NEO- EVOLUTIONARY ORGANICISM}

The key concepts that provide the answers to those two last questions are the notion of "right," leading to a new concept of freedom, and the notion of "market."

What do we, Modern people, mean by "a right"? What is its meaning within neoevolutionary organicism? How can that notion be seen "from outside"? Is this notion different from equivalent notions in other cultures? Again, we will be using an interpretation corresponding to the ancient Greek way of experiencing Being as a contrast to bringing forth the boundaries of a fundamental notion of Modernity; namely that comprised by the pair "right-liberty."

According to Alasdair MacIntyre,

there is no expression in any ancient or medieval language correctly translated by our expression "a right" until near the close of the Middle Ages. The concept lacks any means of expression in Hebrew, Greek, Latin or Arabic.... or in Japanese as late as the mid-nineteenth century (MacIntyre, 1981, p. 67)

Much before MacIntyre, Benjamin Constant, the famous eighteenth century French liberal writer, held that the ancient world had a notion of right (and liberty) radically different from that which animated liberalism in modern times. According to Gray, the difference to which Constant referred can be summarised thus. 
Whereas, for modern men, liberty signifies a protected sphere of non-interference or independence under the rule of law, for the ancient it meant entitlement to a voice in collective decision-making. (Gray, 1986, p. 1).

Let me start by examining the Modern notions of right and liberty so that later they may be compared with the ancient ones.

Although the difference between the modern notions of "liberty" and that of "right" is very subtle, I think that, strictly speaking, the "protected sphere of noninterference or independence under the rule of law" is the Modern concept of "right," rather than that of "liberty." Liberty is the possibility to move within the space provided by such a "protected sphere of non interference." These two notions are particularly meaningful under neo-evolutionary organicism. Let us see how.

Remember that, according to the previous outline of evolutionary organicism, competition among individuals subject to environmental fluctuations, gives rise to a systemic order in the ecological niche. The more evolved the ecological niche, the more perfect is its organisation. This perfectibility means the possibility of maximising each individual's assertion of its identity while strengthening the capacity of the whole niche to maintain its stability. This order, in the case of evolved human societies, is symbolically objectified in laws expressed through language. Now, the law must be such that it provides each individual with the right to assert its identity without threatening the stability of the whole ecological niche. This right is nothing more than the "protected sphere of non-interference or independence under the rule of law." Let us try to get closer to this "sphere of noninterference" in contemporary societies in order to see what is in its inside. What is the individual entitled to within this sphere?

Just as any other biological individual, all the actions of the human individual are given in terms of the imperative to assert its identity and gain a sphere of stability for that identity. This sphere of stability is formally established in laws (order of the ecological niche) under the name of "right." The sphere of stability thus becomes a sort of armour for the competitive battle in which the individual can develop its struggle for assertion of its identity and reinforcement of such an armour. The space where competition takes place is called the "market." Such a space defines the kind of competition and the rules that constitute the boundaries for competition. Competition is, within this ecological order, an economic competition. Individuals compete for the selling and buying of goods and services. Competition must be given in terms of low prices and high quality. The seller that can give lower prices and higher quality obtains more buyers for his products or services. Competition, when it is given under this rule of low prices and high quality, spurs economic growth in the whole society. Economic growth is considered as the fundamental means to assure stability of the human ecological niche and of its individuals. The market becomes, in this way, the great tribunal for deciding everything (or almost everything) concerning the relationships between individuals. The worth of the individual and his works, whether they be shoes, music 
compositions or scientific theories, is decided by the market. If it can be sold then it is good.

On the side of each individual, assertion of identity means, in advanced human ecological niches, the accumulation of private property and the increase of power to compete in the market. This is necessary in order to satisfy his/her individual desires and appetites and to exorcise his/her fears. Those desires and appetites are almost always related to buying and selling.

Now, we can come back and compare the modern notion of right with that of the ancient Greeks (as interpreted by Constant and MacIntyre). According to this interpretation about ancient Greek thinking, right was the "entitlement to a voice in collective decision-making." One could say that this is part of the Modern notion of right. Constant's reply to this doubt is as follows,

while the ancients regarded this [entitlement to a voice in collective decisionmaking] as constituting liberty, they held that all this was compatible with the subjection of the individual to the power of the community.... Among the ancients, the individual, as a sovereign in public affairs, is a slave in all private relations. Among the moderns, on the contrary, the individual, independent in his private life, is even in the freest states a sovereign only in appearance" (Constant B. "Liberty Ancient and Modern", quoted by Gray, 1986, p. 21).

According to this interpretation, the ancient Greek notion of liberty (restricted to free citizens) meant the possibility of transcending into the public domain through rational discursive participation. This transcendental act was given in terms of the use of "practical reason" to clarify and decide on public issues. On the contrary, our modern notion of liberty implies the reinforcement of the protected sphere that surrounds individuality. Thus, it could be said that, whereas the ancient notion of liberty is transcendental with regard to the relationship between the individual and his society, the modern notion of liberty is immanent. This means that, whereas the modern notion of liberty contributes to increasing the proportion of selfconcentration, individualism and selfishness, the ancient notion contributes to dissolving individuality within the community. Obviously this ancient conception is at odds with evolutionary organicism --founded primarily on the fierce opposition between the individual and its community.

We have been comparing an ancient Greek notion of liberty with what we have called a "modern notion" of liberty. But, there is not such thing as a perfectly homogeneous modern notion of liberty. To be sure, according to what we stated before, the Kantian notion of autonomy --pivot of the so called project of the enlightenment, heart of modernity-- is quite different from what we have been calling the "modern notion." Furthermore, as we will discuss as follows, this Kantian notion of autonomy does not fit within neo-evolutionary organicism.

Neo-evolutionary organicism is a deterministic theory. It allows no place for the possibility of a will that goes against its principles. It allows no place for a will 
based primarily on solidarity and common welfare. Living individuals, be they plants, animals or human, are destined to obey the imperative of selfish individualism against other individuals. This imperative acts as a natural causal force (i.e. "human nature") to determine all the individual's actions, thoughts and feelings. In Kant's perspective, this determinism, which is a particular version of the law of the necessary cause, means the denial of "freedom." Such a denial, as Kant discussed in his famous third antinomy commented before, is in contradiction with rational thinking which, in turn, according to Kant, was moved by the interest of freedom. Hence, the process of thinking that generates the theory of neoevolutionary organicism is based on the type of freedom that this very theory denies.

The Kantian notion of liberty was both the exercise of critique and of morality. The exercise of critique means, in a renewed Kantian sense, to go beyond our current context of meanings in order to understand the source of those hidden meanings that determine our way of being. This sort of awareness therefore becomes a challenge to the structures of power that are supported by the corresponding lack of awareness. Critique would thus open the possibility of putting our will at the service of practical reason in order to change certain states of affairs whose maintenance depends on those taken-for-granted meanings. Obviously this idea is at odds with the determinism of evolutionary organicism. The latter denies this possibility of Kantian freedom (autonomy) which challenges power structures. Indeed, as it has been pointed out by many authors in the debate concerning sociobiology (Caplan, 1978), the determinism of what we are calling here neoevolutionary organicism, and in which the title of our session has full meaning, favours the status quo or the present distribution of power. John D. Rockefeller, the great entrepreneur, once said,

The growth of a large business is merely a survival of the fittest... It is merely the working of nature and a law of God (quoted by Allen et. al, in Caplan, 1978, p. 260).

Be it a law of God or a law of nature, neo-evolutionary organicism is supporting the present "international order" to which President George Bush so proudly referred to after the massive killings perpetrated in Iraq by the joint military power of developed nations of the world. This international order is the order of that global ecological niche that we call Earth. Such order allows hunger and death of many children in poor countries that will never have the possibility to compete in the market. This order enhances the sort of selfish individualism that does not allow a place for authentic concern for those who cannot defend themselves and which are condemned to be at the margin of the market.

This last situation is reinforced by the second consequence of determinism against the Kantian notion of liberty. Liberty is, according to Kant, first of all, the exercise of morality. As explained before, if the moral agent is not free, the moral 
problem, depicted in the question, "What ought I do?," disappears. Indeed the new order justified by neo-evolutionary organicism is such that it overcomes the cumbersome problem of morality. Under this new order the market decides over those issues that, in the past, were moral problems.

The Kantian notion of freedom is, of course, "individualistic," in the sense that the individual performs an act of critical reflection. Certainly, within this conception, the individual is not dionysiacly (Nietzsche, 1967) dissolved within his community. The latter could be the case in many non-Western societies in which religion, myth and tradition rule the process of individual dissolution within the community. On the contrary, the Kantian notion of liberty implies a sort of selfretirement of the individual in order to think about the underpinnings of his relationships with other individuals and with nature. Autonomy is thus the foundation of this Kantian type of individualism. The Kantian conception of freedom (autonomy) is, however, individualistic in a sense totally different from neo-evolutionary-organicist individualism. The latter individualism denies the basis of the former individualism, namely autonomy, which leads to the transcendence of the individual towards its community. In its place neo-evolutionary organicism has justified a sort of immanent individualism that becomes, within the human space, selfishness.

\section{A FINAL PERPLEXITY}

After the former discussion concerning the difference between the Kantian notion of liberty and what we had called the "modern" notion of liberty, a question is unavoidable. If there are (at least) two different notions of liberty in modern thinking, why were we talking about the modern notion of liberty as if it were a single notion? Furthermore, the project of the Enlightenment is frequently regarded as the heart of Modernity; and the Kantian notion of autonomy is, in turn, regarded as the propeller of such a project. How can the immanent notion of liberty displace this notion of autonomy and be regarded as the modern notion of liberty?

What we have called Modernity is the historical becoming of a way of experiencing Being which, without precision, is historically placed after the Middle Ages to our days. Those limits are based on the idea that, after the Middle Ages, a great change in the way of experiencing Being began to rule the destiny of many human societies. Such a way of experiencing Being provides the rules for the constitution of the thingness of things, the factualness of facts, the utility of the useful, the constitution of the self, the relationships with other human beings, truth, value, power, etc. To be sure, Modernity has also provided the boundaries for the distinction of this very notion of "Modernity," its historical boundaries and even the notion of "history." Obviously, this last assertion shows the great difficulty, illustrated before by means of Hölderlin's poem, in trying to draw the boundaries of Modernity. One of the usual ways to draw those boundaries is to pay heed to that which seems particular and central to Modernity; for example science and Modern 
technology. When we take a distant look at the panorama of science, bearing in mind the distinction between natural and human sciences, we can observe the domination of two great clusters of theory and practice. On the one hand, we find natural science founded in its onto-epistemological dualist realism which I have examined in more detail elsewhere (Fuenmayor, 1991a). On the other hand, we find liberalism, the political-economic theory of Modernity. We suppose that both of them have been two great outcomes of that way of experiencing Being which, in turn, constitute themselves into forces that reshape and reinforce that way of experiencing Being on which they are founded and which we call Modernity. If they have a common origin and they have acted together, there must be some common principles in the essence of both. I mean "principle," in the sense of the Ancient Greek arche, the ground on which something stands, pervading it, guiding it in its whole structure and essence (Heidegger, 1981, p. 30). However, we cannot easily see such common principles. They seem to have acted, separately of each other. What were then the common principles between, say, Newton's mechanics, Hobbes' initial liberal ideas, the Kantian idea of freedom and practical reason and neoevolutionary organicism?

This question is nothing but a query into the becoming of Modernity and its underlying ontology. An attempt to answer it should shed more light on the boundaries of the meaning of the phrase "environmental fluctuations and cultural change in island societies." We do not have, however, time to attempt a serious reply to such a query; neither am I, with my present state of awareness, prepared for such a task. But let me, as a coda to this piece of inquiry, attempt some ideas about what could be the starting point for such a reply.

As explained before, Kant clearly felt the gap between the project of autonomy of the Enlightenment, that is usually seen within the tradition of Liberalism, and the ontological grounds of natural science. As discussed before, such antinomy was a consequence of the infinite gap between matter and mind on which dualism is based. We also discussed how Kant could not really overcome his antinomy, for he was not aware enough of his own presupposition regarding dualism and natural causality. The only way out of the antinomy --if, as Kant pretended, primacy is given to practical reason-- is to leap out of dualism. The other way is to reject the primacy of practical reason and to deny freedom (autonomy). The path taken by the becoming of our thinking was the second one; so that dualism was kept within modernity. This path has been theoretically supported by neo-evolutionary organicism. This theory becomes, in this way, the solution to the problem of theoretical coherency between natural science and liberalism. But it also constitutes itself as the theoretical justification of our oblivion of practical reason. Indeed, the concern about the practical discussion of social ends and the values underlying those ends, has been replaced by instrumental reason. Neo-evolutionary organicism, the same theory that gives meaning to the title of our session, justifies that we worry only about the means to being successful in the market place. The market and its laws will take care 
of the rest. Under this interpretation of Modernity, the project of the Enlightenment was only an overcome accident in our history. Such history has been pivoted around dualism and its historical realisation.

Maybe as Heidegger, very timidly and just in passing, seems to suggest in a note of his essay, "The Age of the World Pictures" (Heidegger, 1977), the very idea of "right-liberty," conceived as the protected sphere of non-interference is at the very root of dualism. Maybe dualism and the notion of "right" mutually constituted themselves in a self-referential way. Maybe this idea can be seen as the fundamental seed of all our way of experiencing Being. Hence, perhaps by attaining another idea of liberty which means another way of experiencing the other (human being) we could leap out of dualism. Maybe that extraordinary culture of the ancient Greeks which apparently started what we vaguely call Western culture, can serve as an inspiration for that jump out of dualism. Remember, according to one possible interpretation, among the ancient Greeks (like in many other non-European societies) there was not the sort of opposition between a knowing and an acting subject and the rest of what is thus -separated and objectified as the "world." The Greek "bringing-forth" to which we referred before was not founded in that ferocious dualism in which the individual and the assertion of its identity becomes the rationale and the propeller of everything. In any case, this should be the subject of a future inquiry.

Modern technology and neo-evolutionary organicism constitute the great powers that "enframe" our way of experiencing being. It gives support to the "new international order." It gives meaning to the idea that environmental fluctuations cause cultural changes. It also gives meaning to the different forms of ecologism that apparently oppose that structure of power defined by the new international order.

What can we do if we do not like the "new international order"? Leap out of dualism? Can we do this? Remember Hölderlin's verse,

\footnotetext{
Though your soul roams away, winged with its yearning soars

Far beyond your own time, mournful you linger here,

Cold on desolate shores, with

Your own kind, but estranged from them.

(Hölderlin F: Poems and Fragments. Trans. by Michael Hamberger. London.

Routledge and Kegan Paul. p. 59)
}

Are we not condemned to remain on the desolates shores of dualism with our own kind? But, is not this fatal fate of Hölderlin's poem, together with the underlying fabric of the discourse of this very talk, rooted in the same way of experiencing Being that neo-evolutionary organicism is?

\footnotetext{
${ }^{7}$ The idea of the "enframing" power of Modern technology is discussed by Heidegger in his famous essay, "The Question Concerning Technology" (1954).
} 


\section{REFERENCES}

Ackoff R.L. (1974). Redesigning the Future, Wiley, New York.

Aristotle (1928). The works of Aristotle, Oxford University Press, London.

Brown, R. and Lennenberg, E. H. (1954). A Study in Cognition. Journal of Abnormal and Social Psychology, 49.

Caplan, A. L. (ed) (1978). The Sociobiology Debate, Harper and Row, New York.

Deese, J. (1971). Psycholinguistics, Allyn and Bacon Inc., Boston.

Foucault, M. (1966). The Order of Things, Pantheon, New York.

Fuenmayor, R. L. (1991a). The Roots of Reductionism: A Counter-Ontoepistemology for a Systems Approach. Syst. Pract 4, 419-447.

Fuenmayor, R. L. (1991b). The Self-Referential Structure of an Everyday-Living Situation:

A Phenomenological Ontology for Interpretive Systemology. Syst. Pract 4, 449-472.

Fuenmayor, R. L. (1991c). Truth and Openness: An Epistemology for Interpretive Systemology. Syst. Pract 4, 473-490.

Fuenmayor, R. L., and Lopéz-Garay, H. (1991). The Scene for Interpretive Systemology. Syst. Pract 4, 401-418.

Gray, J. (1986). Liberalism, Open University Press, Milton Keynes.

Heidegger, M. (1954). The Question Concerning Technology. In

Basic Writings, Routledge and Kegan Paul, London, pp. 284-317.

Heidegger, M. (1977). The Question Concerning Technology and Other Essays, Harper and Row, New York.

Kant, I. (1784). What is enlightenment? In Kant, I. (ed.), Foundations of the Metaphysics of Morals, Bobbs-Merrill, New York.

Kant, I. (1785). Grounding for the Metaphysics of Morals, trans. J. W. Ellington, Hackett, Indianapolis.

Kant, I. (1786). Critique of Practical Reason, University of Chicago Press, Chicago.

Kant, I. (1787). Critique of Pure Reason, Macmillan, London, 1929.

Levi-Strauss, C. (1963). Structural Anthropology, trans. C. Jacobson and B. Grundfest Schoepf, Basic Book, New York.

Lewis, I. M. (1976). Social Anthropology in Perspective, Penguin, Harmondsworth.

MacIntyre, A. (1981). After Virtue: A Study in Moral Theory, Duckworth and Co., London.

Nietzsche, F. (1967). The Birth of Tragedy. Trans. W. Kaufmann, Vintage Books, Random House, New York.

Scruton, R. (1928). Kant, Oxford University Press, Oxford.

Varela, F. J. (1979). Principles of Biological Autonomy, North Holland, New York. 